\title{
ST
}

Science \& Technology

PAPER - OPEN ACCESS

Pemanfaatan Karbon Aktif Ampas dalam Mereduksi Asam Lemak Bebas (Free Fatty Acid) pada Minyak Goreng Bekas sebagai Biodiesel

\author{
Author : : Reka Sari dkk., \\ DOI $\quad: 10.32734 /$ st.v2i1.329 \\ Electronic ISSN $\quad: 2654-7082$ \\ Print ISSN : :2654-7074
}

Volume 2 Issue 1 - 2018 TALENTA Conference Series: Science \& Technology (ST)

This work is licensed under a Creative Commons Attribution-NoDerivatives 4.0 International License.

Published under licence by TALENTA Publisher, Universitas Sumatera Utara

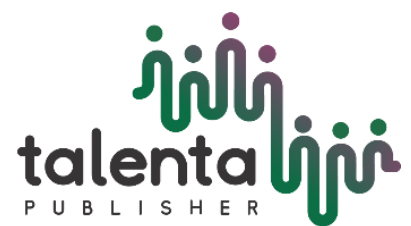




\title{
jibli

\section{Pemanfaatan Karbon Aktif Ampas dalam Mereduksi Asam Lemak Bebas (Free Fatty Acid) pada Minyak Goreng Bekas sebagai Biodiesel}

\author{
Reka M. Saria, Agus Kembaren ${ }^{\mathrm{b}}$ \\ aProgram Studi Kimia, Fakultas Matematika dan Imu Pengetahuan Alam, Universitas Sumatera Utara, Medan 20155, Indonesia

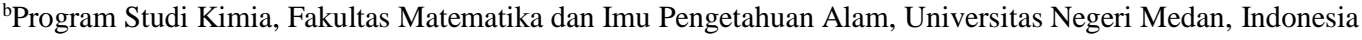

RekaMustikaSari@gmail.com, agus.kembaren@yahoo.co.id

\begin{abstract}
Abstrak
Penelitian ini bertujuan untuk mengetahui bagaimana pretreatment minyak goreng bekas dengan karbon aktif ampas tebu, mengetahui pengaruh variasi katalis terhadap biodiesel dan mengetahui variasi konsentrasi persen berat katalis $\mathrm{NaOH}$ yang menghasilkan FAME biodiesel yang maksimum dengan metode transesterifikasi langsung. Pretreatment minyak dilakukan dengan karbon aktif ampas tebu yang diaktivasi dengan $\mathrm{H}_{3} \mathrm{PO}_{4}$ pada suhu $400^{\circ} \mathrm{C}$ dan massa karbon aktif yaitu $10 \mathrm{~g}$, lalu di uji kualitas minyak berdasarkan standar SNI 01-2901-2006 yang meliputi kadar asam lemak bebas dan bilangan peroksida. Biodiesel yang dihasilkan diuji sesuai SNI 04-7182-2006 yaitu bilangan asam, bilangan iod dan densitas serta mengidentifikasi senyawa pembentuk metil ester dengan GC (Gas Chromatography). Hasil penelitian menunjukkan bahwa pretreatment minyak goreng bekas dengan menggunakan karbon aktif dari ampas tebu efektif menurunkan ALB pada minyak goreng bekas sebesar 0,336\% dan bilangan peroksida 6,99 mek/kg sesuai SNI 06-3730-1995 sehingga dapat dijadikan bahan baku untuk pembuatan biodiesel dengan transesterifikasi langsung menggunakan katalis $1 \% \mathrm{NaOH}$. Didapat densitas biodiesel adalah $0,8599 \mathrm{~g} / \mathrm{mL}$, bilangan iod yaitu $57,3625 \%$ massa dan bilangan asam yaitu $0,6731 \%$. Komposisi FAME oleat, linoleat dan palmitat yaitu $43,4181 \%$, $10,5952 \%, 38,6358$.
\end{abstract}

Kata kunci : Asam lemak bebas; biodiesel; karbon aktif

\section{Pendahuluan}

Biodiesel (metil ester asam lemak atau FAME) merupakan bahan bakar alternatif yang menjanjikan sebagai pengganti bahan bakar fosil dan dapat diproduksi melalui proses transesterifikasi dari minyak nabati dengan alkohol rantai pendek (biasanya metanol dan etanol) dengan adanya katalis. Biodiesel memiliki keunggulan seperti ramah lingkungan, tidak beracun, secara esensial bebas sulfur dan benzena yang karsinogenik, hasil pembakarannya adalah $\mathrm{CO}_{2}$ yang dapat dikonsumsi oleh tumbuhan untuk proses fotosintesis (siklus karbon), dapat teroksigenasi relatif sempurna atau terbakar habis dan terurai secara alami (biodegradable). Biodiesel dapat diperoleh dari minyak tumbuhan yang berasal dari sumber daya alam yang dapat diperbaharui seperti minyak nabati, lemak binatang dan minyak jelantah/jelantah melalui esterifikasi dan atau transesterifikasi [1].

Telah banyak dilakukan penelitian terkait pengolahan biodiesel minyak jelantah. Biodiesel minyak jelantah dengan karakteristik yang belum memenuhi standar SNI. Karakteristik yang diuji dalam penelitian tersebut adalah viskositas dan kandungan ${ }_{2}$ air pada biodiesel yang dihasilkan. Pada penelitian tersebut nilai viskositas yang didapatkan sebesar 7,5 Mm /s untuk biodiesel yang menggunakan metil asetat dan 12,5 Mm /s untuk biodiesel yang menggunakan metanol, angka tersebut berada di luar range yang telah ditetapkan oleh SNI yakni berkisar antara 2,3 - $6 \mathrm{Mm} / \mathrm{s}$. Sedangkan untuk kadar air yang dikandung oleh biodiesel juga lebih besar dari standar SNI yang ditentukan. Tingginya viskositas ini dipengaruhi oleh sisa-sisa asam lemak bebas (FFA) pada minyak jelantah akibat pemanasan yang berulang-ulang saat menggoreng [2]. Dalam penelitian lain didapatkan bahwa terjadi kenaikan nilai 
densitas biodiesel seiring dengan berkurangnya nilai FFA pada minyak jelantah, meski kenaikan densitas tersebut tidak terlalu signifikan yakni sebesar $0,006 \mathrm{~g} / \mathrm{cm}^{3}$ [3]. Oleh karena itu perlu diadakan pretreatment terhadap minyak jelantah sebelum diproses menjadi biodiesel agar kandungan FFA nya dapat diturunkan. Salah satu cara untuk menurunkan FFA pada minyak jelantah adalah dengan merendam arang aktif ampas tebu pada minyak jelantah. Arang aktif ampas tebu dapat digunakan sebagai adsorben minyak jelantah untuk menurunkan FFA yang terkandung didalamnya [4]. Pada penelitian sebelumnya tentang pembuatan karbon aktif dari ampas tebu bahwa karbon aktif dari ampas tebu sebagai adsorben alami pada minyak jelantah dapat menurunkan nilai FFA hingga mencapai $0,0999 \%$ [5].

Oleh karena itu, proses pembuatan biodiesel dalam penelitian ini dilakukan pretreatment minyak jelantah terlebih dahulu agar didapat ALB yang rendah kemudian dilanjutkan dengan proses transesterifikasi langsung dengan menggunakan katalis basa $\mathrm{NaOH}$.

\section{Metode}

\section{Proses Preatreatment Minyak Jelantah.}

\section{Pembuatan Karbon Aktif.}

Ampas tebu yang diperoleh dari sisa-sisa penggilingan sari tebu dikeringkan dibawah terik matahari. Lalu ampas tebu dipotong menjadi bagian yang lebih kecil. Bahan baku yang sudah kering di bakar di dalam tungku pembakaran selama \pm 1 jam, hingga ampas tebu menjadi arang. Arang ampas tebu tersebut di ayak dengan menggunakan ayakan 200 mesh, setelah itu dilakukan proses aktivasi dengan menggunakan $\mathrm{H}_{3} \mathrm{PO}_{4}[1 \mathrm{M}]$ selama 90 menit. Arang yang telah di aktivasi disaring dengan menggunakan saringan buchner, arang yang didapat dimasukkan kedalam tanur dengan suhu pengaktifan $400^{\circ} \mathrm{C}$. Karbon aktif yang telah diaktifkan selanjutnya dicuci dengan aquades untuk menghilangkan residu asam hingga $\mathrm{pH} 7$, selanjutnya karbon aktif tersebut dikeringkan di dalam oven pada suhu $120^{\circ} \mathrm{C}$ selama 2 jam, setelah itu didinginkan di dalam desikator selama 20 menit [6].

\section{Proses Pemurnian Minyak Jelantah.}

Sampel minyak jelantah yang sudah disaring dengan kain tipis dimasukkan sebanyak $100 \mathrm{~g}$ ke dalam beaker glass, minyak jelantah tersebut dipanaskan dengan suhu $90^{\circ} \mathrm{C}$, setelah tercapai suhu reaksi yang diinginkan, karbon aktif dimasukkan dalam minyak sebanyak $10 \mathrm{~g}$, lalu diaduk dengan magnetic stirrer selama 90 menit. Setelah itu minyak disaring, dan filtratnya ditampung, kemudian lakukan pengujian asam lemak bebas, dan bilangan peroksidanya [7].

\section{Pembuatan Biodiesel Minyak Jelantah.}

Memanaskan campuran minyak jelantah dengan perbandingan minyak metanol 1: 6 kemudian ditambahkan katalis $\mathrm{NaOH}$ dengan konmsentrasi $1 \%$ sambil diaduk selama 1 jam dengan suhu $60^{\circ} \mathrm{C}$. Setelah proses pengadukan selesai maka campuran harus didiamkan selama kurang lebih 8 jam hingga terbentuk dua lapisan yang harus dipisahkan. Dimana produk tersebut adalah biodiesel sebagai produk utama yang terletak pada lapisan atas dan berwarna kecoklatan serta gliserol sebagai produk sampingan yang berwarna kehitaman dan terletak pada lapisan bawah. Biodiesel yang sudah didapatkan harus dicuci terlebih dahulu agar bersih dari sisa-sisa katalis yang masih terkandung ataupun kandungan gliserol yang ikut masuk ke dalam biodiesel. Proses pencucian dilakukan dengan menambahkan air dan diaduk. Setelah itu didiamkan selama kurang lebih 4 jam agar biodiesel dan air terpisah (hingga air berwarna putih dan terdapat gumpalan putih [8]. Kemudian ditambahkan $\mathrm{Na}_{2} \mathrm{SO}_{4}$ anhidrat untuk menarik air yang tersisa di dalam metil ester.

\section{Hasil dan pembahasan}

\section{Uji Kualitas Minyak jelantah.}

Sampel minyak jelantah yang digunakan merupakan minyak yang diambil dari sisa penggorengan ayam goreng. Minyak jelantah tersebut disaring dengan menggunakan kain tipis, sehingga sisa-sisa penggorengan pada minyak tersebut dapat hilang, setelah penyaringan dilakukan pengujian pada minyak goreng, diantaranya kadar air, asam lemak bebas, dan bilangan peroksida. Berikut ini Tabel 1 hasil uji minyak jelantah: 


\begin{tabular}{lll}
\hline Kadar Air (\%) & Asam Lemak Bebas (\%) & Bilangan Peroksida (mek/Kg) \\
\hline 11,47 & 4,16 & 47,90 \\
\hline
\end{tabular}

Pada Tabel 1 terlihat hasil uji minyak goreng yang meliputi kadar air, asam lemak bebas, dan bilangan peroksida sudah melewati standar SNI (01-2901-2006), dimana berdasarkan standar yang ditetapkan kadar air pada minyak goreng adalah $0,5 \%$, kadar asam lemak bebas pada minyak goreng adalah $0,5 \%$ dan standar bilangan peroksida pada minyak goreng adalah $10 \%$.

\section{Pretreatment Minyak jelantah.}

Pada pembuatan karbon aktif dari ampas tebu ini, metode aktivasi yang digunakan adalah metode aktivasi kimia yaitu dengan cara mencampurkan activating agent dengan karbon yang dihasilkan dari hasil karbonisasi. Asam posfat yang digunakan berkonsentrasi $1 \mathrm{M}$, asam posfat tersebut dicampur dengan karbon/arang yang telah ditimbang. Campuran tersebut diaduk dengan magnetik stirer selama 90 menit. Pengadukan dan pemanasan ini bertujuan agar karbon terimpregnasi sehingga $\mathrm{H}_{3} \mathrm{PO}_{4}$ dan kandungan air pada larutan $\mathrm{H}_{3} \mathrm{PO}_{4}$ dapat menguap sehingga $\mathrm{H}_{3} \mathrm{PO}_{4}$ dapat bereaksi dengan karbon dan pori-pori dapat terbentuk. Setelah proses pengadukan dan pemanasan, didapatkan campuran telah berbentuk slurry berwarna hitam.

Setelah proses aktivasi dengan bahan kimia, selanjutnya dimasukkan ke dalam furnace untuk tahap pengaktifan. Setelah proses aktivasi, karbon aktif yang dihasilkan masuk dalam tahap pencucian. Pencucian ini dilakukan untuk menghilangkan sisa-sisa bahan kimia yang digunakan sebagai activating agent dan hasil reaksi sewaktu aktivasi yang mungkin menutupi permukaan pori-pori karbon aktif. Jadi pencucian ini bertujuan agar karbon aktif yang didapat lebih murni atau tidak terkontaminasi dengan zat lain.

\section{Analisa Kadar Asam Lemak Bebas.}

Analisa penentuan asam lemak bebas dilakukan dengan cara titrasi menggunakan $\mathrm{KOH} 0,1 \mathrm{~N}$ yang ditambahkan indikator phenolphthalein (PP) hingga terbentuk larutan merah muda (lembayung). Standar SNI minyak goreng untuk asam lemak bebas adalah 0,5\% (SNI 01-2901-2006). Berdasarkan standar SNI untuk kadar asam lemak bebas, minyak jelantah awalnya tidak layak dikonsumsi (Tabel 1). Namun, perlakuan secara adsorbsi menggunakan karbon aktif dari ampas tebu menjadikan minyak hasil regenerasi lebih aman dan dapat digunakan untuk keperluan lainnya, hal ini karena minyak hasil regenerasi menghasilkan nilai asam lemak bebas semakin kecil $(\leq 0,5 \%)$.

Terjadinya penurunan asam lemak bebas setelah di adsorpsi dengan karbon aktif dari ampas tebu disebabkan oleh adanya gugus silanol ( $\mathrm{Si}-\mathrm{OH})$ yang terbentuk dari senyawa $\mathrm{SiO}_{2}$ dalam karbon yang telah teraktivasi dengan asam. Semakin banyak jumlah $\mathrm{SiO}_{2}$ pada adsorben (jumlah $\mathrm{SiO}_{2}$ dalam ampas tebu sebesar $71 \%$ ), maka akan meningkatkan jumlah gugus Si-OH (silanol) pada permukaan adsorben. Gugus silanol tersebut yang akan menyerap asam lemak bebas (Free Fatty Acid/FFA). Atom hidrogen dari gugus silanol akan berikatan dengan gugus oksigen karbonil $(\mathrm{C}=\mathrm{O})$ pada asam lemak bebas sehingga molekul asam lemak bebas dapat teradsorpsi pada permukaan karbon aktif [9]. Kemampuan ini yang menyebabkan kedua adsorben dapat menurunkan asam lemak bebas dalam minyak jelantah.

Sehingga berdasarkan hasil penelitian ini pada pretreatment minyak jelantah dengan karbon aktif ampas tebu didapat asam lemak bebas pada suhu $400^{\circ} \mathrm{C}$ sebanyak $10 \mathrm{~g}$ karbon aktif yaitu 0,336 \% sesuai (SNI 01-2901-2006) dan layak sebagai bahan baku biodiesel dengan proses transesterifikasi langsung.

\section{Analisa Bilangan Peroksida.}

Kerusakan minyak pada penelitian ini ditentukan dengan menggunakan parameter bilangan peroksida. Peroksida merupakan produk awal terjadinya kerusakan pada minyak goreng akibat terjadinya oksidasi pada proses pemanasan.

Mengacu syarat mutu minyak goreng menurut SNI (01-2901-2006), untuk bilangan peroksida (maksimal 10 mek/kg), terlihat bahwa minyak jelantah awal sudah rusak karena kadar peroksidanya yang tinggi yaitu $(43,11$ $\mathrm{mek} / \mathrm{kg}$ ). Hasil perhitungan bilangan peroksida pada minyak yang telah dimurnikan diperoleh $6,99 \mathrm{mek} / \mathrm{kg}$ sesuai dengan Standar Nasional Indonesia (01-2901-2006). Ini menunjukkan bahwa adsorben yang digunakan mampu menurunkan kandungan senyawa peroksida pada minyak goreng. Di sisi lain, ampas tebu mengandung selulosa yang kaya akan gugus hidroksil yang bersifat polar sehingga memiliki afinitas yang besar terhadap zat terlarut yang 
polar. Senyawa peroksida yang terdapat dalam minyak mengandung gugus peroksida yang bersifat polar sehingga mudah diserap oleh selulosa dari ampas tebu. Kemampuan ini yang menyebabkan adsorben dari ampas tebu dapat menurunkan kadar PV dalam minyak jelantah.

\section{Uji Kualitas Biodiesel}

\section{Analisa Densitas.}

Densitas merupakan perbandingan massa dengan volume tertentu dari suatu fluida pada temperatur tertentu. Densitas minyak adalah massa minyak per satuan volum pada suhu tertentu. Penentuan densitas biodiesel dilakukan dengan cara piknometer ditimbang pada $40^{\circ} \mathrm{C}$ kemudian diisi dengan sampel. Suhu piknometer dijaga pada $40^{\circ} \mathrm{C}$ dan ditimbang.

Nilai densitas biodiesel dihasilkan $0,8599 \mathrm{~g} / \mathrm{mL}$ masih dalam range standarisasi SNI berarti masih memenuhi syarat uji densitas. Nilai densitas yang didapat sesuai dengan syarat mutu biodiesel SNI 04-7182-2006 yaitu 0,850-0,890 $\mathrm{g} / \mathrm{mL}$.

Jika biodiesel mempunyai massa jenis melebihi ketentuan, akan terjadi reaksi tidak sempurna pada konversi minyak nabati. Biodiesel dengan mutu seperti ini seharusnya tidak digunakan untuk mesin diesel karena akan meningkatkan keausan mesin, emisi, dan menyebabkan kerusakan pada mesin [10].

\section{Analisa Bilangan Asam.}

Bilangan asam diperoleh dari pengujian asam lemak bebas (FFA). Angka asam yang tinggi merupakan indikator biodiesel masih mengandung asam lemak bebas. Berarti, biodiesel bersifat korosif dan dapat menimbulkan kerak pada injektor mesin diesel. Biodiesel dinyatakan mengandung asam lemak siklopropenoid yang akan berpolimerisasi akibatnya injektor mesin diesel akan tersumbat.

Pengaruh katalis basa terhadap minyak dengan kandungan asam lemak bebas yang tinggi akan mengakibatkan asam lemak bebas bereaksi dengan katalis yang ditambahkan dan selanjutnya bereaksi menghasilkan sabun [11]. Selain itu, sabun juga akan meningkatkan viskositas dari biodiesel dan mengganggu proses pemisahan gliserol. Penyebab lainnya yaitu pengeringan biodiesel yang kurang sempurna sehingga masih ada sedikit campuran air pada biodiesel yang mengakibatkan bilangan asam semakin tinggi. Reaksi hidrolisis antara minyak dan air akan menghasilkan asam lemak dan gliserol, menurut reaksi:

$$
\mathrm{C}_{3} \mathrm{H}_{5}(\mathrm{COOR})_{3}+\mathrm{H}_{2} \mathrm{O} \rightleftarrows \mathrm{C}_{3} \mathrm{H}_{5}(\mathrm{OH})_{3}+3 \mathrm{HOOCR}
$$

Pada pembuatan metil ester dengan cara transesterifikasi, apabila bahan baku mempunyai ALB tinggi maka akan dapat menyebabkan terjadi blocking yaitu metanol yang seharusnya bereaksi dengan trigliserida terhalang oleh pembentukan sabun. Munculnya angka asam yang cukup tinggi ini dimungkinkan juga karena dibiarkannya terlalu lama produk setelah proses transesterifikasi [12].

Dari hasil penelitian bilangan asam didapat 0,6731\% memenuhi syarat mutu biodiesel sesuai SNI 04-7182-2006 kurang dari $0,8 \%$.

\section{Analisa Bilangan Iod.}

Bilangan iod merupakan parameter suatu minyak atau lemak yang dinyatakan dalam perbandingan besarnya iod yang diserap per 100 gr sampel. Uji bilangan iod dapat diaplikasikan pada trigliserida dan asam bebas lemak jenuh yang terhidrogenasi.

Semakin besar bilangan iod, maka semakin banyak ikatan rangkap pada minyak sehingga kadar oksirannya tinggi. Semakin banyak derajat ketidakjenuhan maka semakin bagus kualitas biodiesel yang dihasilkan. Kandungan senyawa asam lemak tak jenuh meningkatkan ferpormansi biodiesel pada temperatur rendah karena senyawa ini memiliki titik leleh (Melting Point) yang lebih rendah sehingga berkorelasi terhadap clout point dan puor point yang rendah. Namun disisi lain banyaknya senyawa lemak tak jenuh di dalam biodiesel memudahkan senyawa tersebut bereaksi dengan oksigen di atmosfer. Biodiesel dengan kandungan bilangan iod yang tinggi akan mengakibatkan tendensi polimerisasi dan pembentukan deposit pada injector noozle dan cincin piston pada saat mulai pembakaran.

Terjadi penurunan bilangan iod seiring pertambahan katalis, ini disebabkan karena adanya pelakuan pemanasan dalam proses pembuatan biodiesel. Adanya pemanasan tersebut kemungkinan menyebabkan ikatan-ikatan tak jenuh dalam asam lemak penyusun minyak goreng bekas mengalami degradasi oleh suhu, sehingga bilangan iod pada 
biodiesel lebih rendah. Nilai bilangan iod dihasilkan 57,3625\% massa sesuai dengan syarat mutu biodiesel SNI 047182-2006 maksimal 115.

\section{Analisa GC.}

Dari analisa Gas Chromatography yang dilakukan, proses transesterifikasi sebagai upaya untuk memanfaatkan limbah minyak goreng bekas sebagai bahan baku pembuatan biodiesel dapat menghasilkan metil ester. Analisa ini dilakukan untuk mengetahui terbentuknya metil ester. Analisis ini menghasilkan puncak-puncak spektra yang masing-masing menunjukkan jenis metil ester yang spesifik.

Hasil GC pada minyak goreng bekas didapat yaitu pada waktu retensi 10.941 yaitu palmitat (C16) sebanyak 39,1926\%, oleat (C18:1C) dengan waktu retensi 15.218 sebanyak 42.47844\%, linoleat (C18:2C) dengan waktu retensi 16.449 sebanyak $10.25387 \%$.

Senyawa utama yang merupakan komponen-komponen utama dari senyawa yang terkandung dalam biodiesel tersebut dilihat dari besarnya prosentase senyawa. Senyawa lain yang dihasilkan dari analisa dengan Kromatografi Gas, kemungkinan merupakan alkil ester turunan dari masing-masing asam lemaknya. Terlihat bahwa asam lemak yang dominan penyusun biodiesel minyak goreng bekas adalah palmitat, oleat dan linoleat. Sedangkan oleat adalah yang paling dominan dengan persentase FAME paling tinggi.

\section{Kesimpulan}

Kesimpulan yang diambil dari penelitian ini adalah:

1. Pretreatment minyak goreng bekas dengan menggunakan karbon aktif dari ampas tebu yang diaktivasi dengan larutan $\mathrm{H}_{3} \mathrm{PO}_{4} 1 \mathrm{M}$ dan ditanur pada suhu $400^{\circ} \mathrm{C}$ efektif menurunkan ALB pada minyak goreng bekas sebesar 0,336\% dan bilangan peroksida $6,99 \mathrm{mek} / \mathrm{kg}$ sehingga dapat dijadikan bahan baku untuk pembuatan biodiesel dengan transesterifikasi langsung.

2. Densitas biodiesel yang dihasilkan adalah $0,8599 \mathrm{~g} / \mathrm{mL}$, bilangan iod yaitu $57,3625 \%$ massa dan bilangan asam yaitu $0,6731 \%$.

Komposisi FAME biodiesel yaitu oleat, linoleat dan palmitat adalah 43,4181\%, 10,5952\%, 38,6358.

\section{Referensi}

[1] Ulfiati., Totok, Herbi S., (2010), Pembuatan Biodiesel dari Biji Alpukat dengan Proses Tranesterifikasi, Hasil Penelitian, Fakultas Teknologi Industri Universitas Pembangunan Nasional "Veteran"

[2] Riswan, Akbar., (2010), Karakteristik Biodiesel dari Minyak Jelantah dengan Menggunakan Metil Asetat Sebagai Pensuplai Gugus Metil, Fakultas Teknologi Kelautan Institut Teknologi Sepuluh Nopember

[3] Gareso, P.L., dkk., (2010), Karakterisasi Sifat Fisis Biodiesel sebagai Sumber Energi Alternatif, Jurnal Sains MIPA 16 (2), ISSN 1978-1873

[4] Wijayanti, Ria., (2009), Arang Aktif dari Ampas Tebu sebagai Adsorben pada Pemurnian Minyak Goreng Bekas., Skripsi, FMIPA, Institut Pertanian Bogor, Bogor

[5] Ramdja, Fuadi., Lisa, Febrina., Daniel, Krisdianto., (2010), Pemurnian Minyak Jelantah Menggunakan Ampas Tebu sebagai Adsorben, Jurnal Teknik Kimia 17 (1)

[6] Shofa.,(2012), Pembuatan Karbon Aktif Berbahan Baku Ampas Tebu Dengan Aktivasi Kalium Hidroksida., Skripsi, FT, Universitas Indonesia, Depok.

[7] Sholikhah, Faizatu., (2008), Pengaruh Penambahan Karbon Aktif dari Tongkol Jagung Terhadap Penurunan Angka Peroksida Minyak Goreng., Skripsi, Fakultas Sains dan Teknologi, Universitas Islam Negeri Sunan Kalijaga, Yogyakarta

[8] Tatik, Farihah., dan Lizda, Johar Maharni., (2013), Pengaruh Ukuran Arang Aktif Ampas Tebu sebagai Biomaterial Pretreatment terhadap Karakteristik Biodiesel Minyak Jelantah, JURNAL TEKNIK POMITS 2 (2) ISSN: 2337-3539

[9] Tanjaya, A., (2006), Aktivasi Bentonit Alam Pacitan sebagai Bahan Penjerap pada Proses Pemurnian Minyak Sawit.Jurnal Teknik Kimia Indonesia.5(1):429-434

[10] Tejo, Laksono., (2013), Pengaruh Jenis Katalis NaOH dan KOH serta Rasio Lemak dengan Metanol Terhadap Kualitas Biodiesel Berbahan Baku Lemak Sapi., Skripsi, Fakultas Peternakan, Universitas Hasanuddin, Makassar

[11] Truck, R., (2002), Method for Producing Fatty Acid Esters of Monovalent Alkyl Alcohols, McNeff Research Consultants, Inc, Anoka

[12] Samios, D., Pedrotti, F., Nicolau, A., Reinautt, QB., Martini, DD., Dalcin, FM., (2009), A Transesterification Double Step Process - TDSP for Biodiesel Preparation from fatty Acids Triglycerides, Fuel Processing Technology 90: 599 - 605 